\title{
Chemical Hazard in Work Place and Mass Media
}

\section{Massimo Cecaro}

Director of Accredited Training Centre, in agreement with University of Camerino, Italy

Mass media campaigns can produce positive changes or prevent negative changes in health-related behaviors across large population [1]. It is important to improve a good culture of the safety in the workplace. We have poor communication about the chemical hazard in the workplace. "Exposure to hazardous chemicals is one of the most serious threats facing American workers today," said U.S. Secretary of Labor Hilda Solis. "Revising OSHA's Hazard Communication standard will improve the quality and consistency of hazard information, making it safer for workers to do their jobs and easier for employers to stay competitive [2]. The mass media needs to give the correct information about this topic, and specifically about the prevention of this hazard. There are 750,000 hazardous chemicals used in the workplace around the world, hundreds more are added every year. The Health hazard, regarding hazardous chemicals, is properties of a chemical that have the potential to cause adverse health effects. Exposure usually occurs through inhalation, skin contact or ingestion. Adverse health effects can be acute (short term) or chronic (long term). Typical acute health effects include headaches, nausea or vomiting and skin corrosion, while chronic health effects include asthma, dermatitis, nerve damage or cancer [3]. As the connection between work, environment and health is more and more strong and the workplaces become more complex, physicians who practice occupational and environmental medicine play an increasingly visible role in preventing diseases and promoting wellness among workers [4]. Communication has a crucial role in enhancing workers' safety behaviours. In order to guarantee workers' safety and health, both the RSPP and the occupational health physician (OHP) need to be involved in frequent and personal relationships with other members in the organization [5]. The diffusion of recent regulations on work safety has captured mass-media's interest on work accidents. Results showed that print media are accurate in reporting news, but they do not serve as source of education in work safety's issues. Information is mainly focused around catastrophic events, with headlines inducing negative emotions are important to consider the transformation of media's role in promoting work safety [6].

\section{References}

1. Melanie AW, Barbara L, Robert CH (2010) Use of mass media campaigns to change health behavior. Lancet 376: 1261-1271.

2. https://www.osha.gov/html/a-z-index.html

3. Managing risks of hazardous chemicals in the workplace. Code of Practice.

4. Isolani, Cecaro (2013) The Leading Role of the Occupational Health Physician in Workpl ace Prevention and the Importance of Knowledge and Communication Abilities. J Mass Communicat Journalism S1: 001.

5. Cecaro M, Isolani L, Passamonti C (2010) Communication-based strategies to improve workers' health and safety: the role of the Responsible for Prevention and Protection Service (RSPP) and the Occupational Health Physician (OHP). G Ital Med Lav Ergon 32: 231.

6. Cecaro M, Bernardini M, Isolani L, Passamonti C (2010) Occupational medicine and communication: which role for print media? G Ital Med Lav Ergon 32: 228230
*Corresponding author: Massimo Cecaro, Director of Accredited Training Centre,
in agreement with University of Camerino, Italy, Tel: 0039-3337844355; Fax: 0733280159; E-mail: massimo@cecaro.com

Received November 19, 2013; Accepted November 20, 2013; Published November 25, 2013

Citation: Cecaro M (2013) Chemical Hazard in Work Place and Mass Media. J Mass Communicat Journalism S1: 004. doi:10.4172/2165-7912.S1-004

Copyright: (c) 2013 Cecaro M. This is an open-access article distributed under the terms of the Creative Commons Attribution License, which permits unrestricted use, distribution, and reproduction in any medium, provided the original author and source are credited. 